\title{
Analysis and Study on Classroom Air Quality in Post-epidemic Era
}

\author{
ZhiMei Wen ${ }^{1, *}$ \\ ${ }^{1}$ School of Energy and Civil Engineering, Shandong Huayu University of Technology, Dezhou, Shandong 253000, China
}

\begin{abstract}
Taking No.21 Teaching Building of a university in Dezhou as the test site, this paper investigates the interviewees' (college students) satisfaction with the thermal environment of the classroom and the reasons for dissatisfaction, learning efficiency and influencing factors, and analyzes the influence of users' personalized characteristics on the thermal comfort of the interviewees by means of measurement and investigation methods. During the field survey and investigation, it is found that the classroom environment can guarantee the learning efficiency of the vast majority of interviewees, but the air quality needs to be improved. This paper aims to provide some reference for the design of indoor space and environment of university classrooms in the post-epidemic era.
\end{abstract}

\section{Introduction}

With the emergence of new coronavirus, people have increasingly higher requirements for indoor air quality. Classroom is the main place for students to study, and its thermal environment and air quality have a great impact on students' thermal comfort, health and learning efficiency. However, in the same environment, due to gender, age, weight and height and other factors, students' thermal comfort feeling is also different. Understanding the correlation between students' personalized characteristics and building thermal environment is helpful to build a comfortable environment according to students' characteristics, improve the design of building thermal environment, and thus improve students' thermal comfort and learning efficiency.

Liu Kuixing et al.[1] found that the Neutral Temperature of users in winter was lower than that in autumn. The study of Cao Bin[2] showed that the neutral temperature was the highest in summer. Cao Hongfang et al.[3] found in their study that women prefer a warm environment in summer compared with men. Lan L et al.[4] found that the skin temperature of women is lower than that of men, and women are more sensitive to the cold environment. Dear R D et al.[5] found that the neutral temperature of children is lower than that of adults. In addition to gender, the user's weight also affects their thermal comfort. Rupp R F et al.[6] found that overweight people are more likely to suffer from warm-induced discomfort. Samar Thapa[7] found that subjects with lower body weight preferred higher neutral temperature. From the above analysis, it can be seen that existing studies mostly focus on the relationship between user's personalized characteristics (gender, body type) and temperature, but there are few studies on the correlation between user's personalized characteristics and indoor air relative humidity and $\mathrm{CO}_{2}$ volume fraction.

The problems of indoor thermal environment and air quality of traditional classrooms exposed during the epidemic period should arouse people's great attention. How to effectively improve the thermal environment and air quality of university classrooms, continuously improve the learning efficiency of students, more reasonable separation of indoor space, and carry out green and healthy indoor environment design are the new development direction of university classroom design in the post-epidemic era. In this paper, the method of measurement and investigation is adopted, and the No.21 Teaching Building of a college in Texas is taken as the test site. Through investigating the interviewees' satisfaction with the thermal environment of the classroom (and the reasons for dissatisfaction), the evaluation of learning efficiency (and the influencing factors), the influence of users' personalized characteristics on the thermal comfort of the interviewees is analyzed.

\section{Research contents and methods}

\subsection{The research content}

Environmental parameters (temperature, relative humidity, carbon dioxide volume fraction) in the classroom were monitored. Questionnaires were sent to students in the classroom to collect the evaluation of interviewees with different genders and body types on thermal comfort, and the relationship between user personalized differences and temperature, relative humidity, and carbon dioxide volume fraction was

\footnotetext{
"Corresponding author:* ZhiMei Wen: 354187917@qq.com
} 
analyzed. In this paper, body mass index (BMI) was used to represent the user's body shape, and the calculation formula of BMI was as follows:

$$
I_{B M I}=\frac{m}{h^{2}}
$$

In the formula: $I_{B M I}$ - body mass index; $m$-- volume, kg; h -- Height, m.

\subsection{The test place and time}

The test place is located in No. 21 Teaching Building of a university in Dezhou, and the test time is October 2020. Typical classrooms for the test are shown in Figure 1. All the interviewees were sitting quietly.

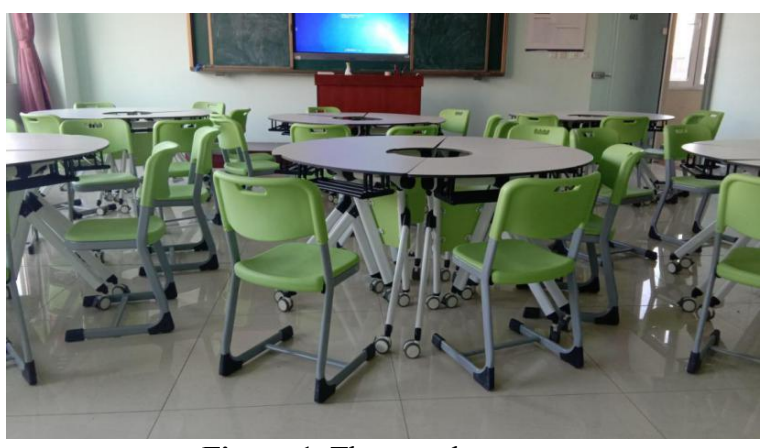

Figure 1. The test classroom

\subsection{The test method}

During the period of measurement and investigation, classes and self-study classrooms were randomly selected. The testing instruments used, as well as the range and accuracy of the instruments are shown in

Table 1 below.

Table 1. Test instrument and main test parameters

\begin{tabular}{|c|c|c|c|c|}
\hline Test parameters & Instrument & Scope & precision & Resolution \\
\hline PM2.5 & $\begin{array}{c}\text { Professional PM2.5 } \\
\text { haze instrument }\end{array}$ & $0-999 \mu \mathrm{g} / \mathrm{m}^{3}$ & $\pm 10 \% \mu \mathrm{g} / \mathrm{m}^{3}$ & $0.1 \mu \mathrm{g} / \mathrm{m}^{3}$ \\
\hline PM10 & Air quality detector & $0-999 \mu \mathrm{g} / \mathrm{m}^{3}$ & $\pm 10 \% \mu \mathrm{g} / \mathrm{m}^{3}$ & $0.1 \mu \mathrm{g} / \mathrm{m}^{3}$ \\
\hline $\mathrm{CO}$ & Air quality detector & $0-999 \mu \mathrm{g} / \mathrm{m}^{3}$ & $\pm 10 \% \mu \mathrm{g} / \mathrm{m}^{3}$ & $0.1 \mu \mathrm{g} / \mathrm{m}^{3}$ \\
\hline $\mathrm{CO}_{2}$ & $\begin{array}{l}\text { Carbon dioxide } \\
\text { detector }\end{array}$ & 0-3000ppm & $\pm 5 \%$ & $1 \mathrm{ppm}$ \\
\hline Tempe-rature & $\begin{array}{l}\text { High precision } \\
\text { temperature and } \\
\text { humidity recorder }\end{array}$ & $-40-100^{\circ} \mathrm{C}$ & $0.3^{\circ} \mathrm{C}$ & $0.1^{\circ} \mathrm{C}$ \\
\hline Humidity & $\begin{array}{l}\text { High precision } \\
\text { temperature and } \\
\text { humidity recorder }\end{array}$ & $0-100 \% \mathrm{RH}$ & $2 \%$ & $0.1 \% \mathrm{RH}$ \\
\hline
\end{tabular}

When the paper questionnaire was sent to the interviewees, the environmental parameters in the classroom were monitored and recorded. The main contents of the questionnaire include personalized characteristic parameters (gender, age, height, weight, etc.), interviewees' satisfaction with the classroom environment and reasons for dissatisfaction, thermal sensation, humidity sensation, stigmatize sensation, as well as interviewees' evaluation of learning efficiency and influencing factors. A total of 332 questionnaires were collected. In order to ensure the accuracy of the analysis results and avoid the impact of human thermal activities, the questionnaires of the interviewees who stayed in the classroom for less than $30 \mathrm{~min}$ were removed. Finally, 298 valid questionnaires were obtained, including 156 male questionnaires and 142 female questionnaires.

\section{Results and analysis}

During the period of measurement and investigation, the temperature in the classroom was between $24-30^{\circ} \mathrm{C}$ and the relative humidity was below $70 \%$.

\subsection{Subjective evaluation}

\subsubsection{Satisfaction with classroom environment and reasons for dissatisfaction}

The proportion of respondents' overall satisfaction with classroom environment is shown in Table 2 below. The reasons for interviewees' dissatisfaction with the classroom environment are shown in Table 3 below.

As can be seen from Table 2, more than half of the students are satisfied with the classroom environment, accounting for $58.09 \%$. Those who thought the classroom environment was ordinary followed by $28.1 \%$ of the total. According to the survey results, the classroom environment can meet the needs of most interviewees.

Table 2. Overall satisfaction of interviewees with classroom environment

\begin{tabular}{|c|c|}
\hline Satisfaction & The proportion/\% \\
\hline Not satisfied & 6.49 \\
\hline
\end{tabular}




\begin{tabular}{|c|c|}
\hline Satisfaction & The proportion/\% \\
\hline General & 28.1 \\
\hline Satisfied & 58.09 \\
\hline Very satisfied & 7.32 \\
\hline
\end{tabular}

As can be seen from Table 3, among the respondents who answered this question, the reasons for dissatisfaction with the classroom environment mainly focused on air freshness, room layout, personnel density and noise, while the number of people who were dissatisfied with indoor temperature, relative humidity and lighting was limited.

According to the analysis of the reasons, the survey was conducted in October. Most of the classrooms had Windows open, so the indoor air was relatively fresh. However, some shaded classrooms had closed doors and Windows, which resulted in poor indoor air quality.

The area of individual classrooms is small, and the number of unsatisfied people increases due to the increase of personnel density.

Table 3. Reasons for interviewees' dissatisfaction with classroom environment

\begin{tabular}{|c|c|}
\hline $\begin{array}{c}\text { Reasons for } \\
\text { Dissatisfaction }\end{array}$ & The number/person \\
\hline Indoor temperature & 30 \\
\hline Indoor relative humidity & 28 \\
\hline Air freshness & 50 \\
\hline Lighting conditions & 31 \\
\hline Noise level & 46 \\
\hline $\begin{array}{c}\text { Room layout and } \\
\text { personnel density }\end{array}$ & 99 \\
\hline
\end{tabular}

\subsubsection{Evaluation and influencing factors of learning efficiency}

The respondents' evaluation of learning efficiency and the influencing factors are shown in Table 4 and 5 respectively. As can be seen from Table 4, interviewees with average learning efficiency account for the vast majority, followed by those who are relatively satisfied.

Table 4. Respondents' evaluation of learning efficiency

\begin{tabular}{|c|c|}
\hline Evaluation content & The proportion/\% \\
\hline Not satisfied with & 20.22 \\
\hline General & 50.16 \\
\hline Satisfied & 26.64 \\
\hline
\end{tabular}

Very satisfied

2.98

As can be seen from Table 5, among the respondents who answered this question, the influencing factors of low learning efficiency mainly focus on staying up late the night before and poor mental condition, while only 35 respondents reported that the hot and humid environment in the classroom was not good. In addition to those who chose specific reasons, another 21 respondents chose the option of "none of the above". After further communication, we learned that the main reason was the decline in learning efficiency caused by electronic devices such as mobile phones and computers. Therefore, the classroom environment can ensure the learning efficiency of the vast majority of interviewees.

Table 5. Influencing factors of low learning efficiency

\begin{tabular}{|c|c|}
\hline reason & $\begin{array}{c}\text { The } \\
\text { number/person }\end{array}$ \\
\hline $\begin{array}{c}\text { Staying up late the night before and } \\
\text { feeling out of shape }\end{array}$ & 51 \\
\hline I'm not interested in this course & 37 \\
\hline $\begin{array}{c}\text { Being in a bad mood for other reasons } \\
\text { Illness leads to poor condition }\end{array}$ & 27 \\
\hline $\begin{array}{c}\text { The hot and humid environment in } \\
\text { the classroom is not good }\end{array}$ & 6 \\
\hline None of the above & 21 \\
\hline
\end{tabular}

\subsection{The influence of individual characteristics}

\subsubsection{The gender}

Thermal sensation is measured on seven levels: very cold, cold, a little cold, neutral, a little hot, hot, very hot. The respondents' votes were classified according to the indoor temperature at that time and gender. It was found that when the indoor temperature was $26-28^{\circ} \mathrm{C}$, the thermal sensation of most male and female interviewees was neutral. At $24-26^{\circ} \mathrm{C}$, the thermal feeling of most male and female interviewees is a little cold. At $28-30^{\circ} \mathrm{C}$, the thermal feeling of most male and female interviewees is a little hot. In general, women have a higher neutral temperature than men.

Moisture sensation uses 5 level indicators: very wet, moist, moderate, dry, very dry. The respondents' votes were classified according to indoor relative humidity and gender at that time. It is found that when the relative humidity is between $50 \%$ and $60 \%$, the humidity sensation of most male and female interviewees is moderate. In general, women feel drier than men at the same relative humidity.

The feeling of oppressivity adopts 5-level indicators: not oppressivity, somewhat oppressivity, relatively oppressivity, very oppressivity, very oppressivity. The respondents' votes were classified according to the 
indoor $\mathrm{CO}_{2}$ volume fraction at that time and gender. As can be seen from the voting results, the feeling of oppressability of the interviewees mainly focuses on the feeling of somewhat oppressability and relatively oppressability. In addition, within the distribution range of $\mathrm{CO}_{2}$ volume fraction, all interviewees expressed somewhat oppressability and relatively oppressability. Even if the $\mathrm{CO}_{2}$ volume fraction in the classroom was less than $1000 \times 10^{-6}$, the interviewees still felt a little suffocated. When the $\mathrm{CO}_{2}$ volume fraction in the classroom was higher than $1500 \times 10^{-6}$, there was no significant increase in the number of respondents who said they were somewhat or relatively oppressed. Therefore, the relationship between the feeling of suffocation and the volume fraction of $\mathrm{CO}_{2}$ is not close. At the same $\mathrm{CO}_{2}$ volume fraction in the classroom, female respondents were more likely to feel suffocated than male respondents, indicating that women were more likely to feel suffocated.

\subsubsection{The size}

According to the body mass index (IBMI), the body type of the interviewees was divided into three categories: IBMI $<18.5$ was considered as underweight body type, IBMI between 18.5-23.9 was considered as normal body type, and IBMI $>23.9$ was considered as overweight body type. According to the survey results, the neutral temperature of overweight people is about $26.4^{\circ} \mathrm{C}$, and the neutral temperature of normal and lean people is about $27.2^{\circ} \mathrm{C}$, indicating that the neutral temperature of obese people is lower than that of normal and lean people. According to the survey results, obese people are more sensitive to the perception of relative humidity, while normal and lean people are not so sensitive. When the relative humidity in the classroom is between $40 \%$ and $60 \%$, the wetness feeling of overweight people is moderate. When the $\mathrm{CO}_{2}$ volume fraction in the classroom was the same, there was no significant difference in the feeling of oppressive among the three body types, and there was no significant discomfort with the increase of $\mathrm{CO}_{2}$ volume fraction in the classroom.

\section{Conclusion}

Taking No. 21 Teaching Building of a college in Dezhou as the test site, this paper adopts the method of field measurement and investigation to investigate the interviewees (college students) 'satisfaction with the thermal environment of the classroom and the reasons for their dissatisfaction, the evaluation of learning efficiency and the influencing factors, and analyzes the influence of users' personalized characteristics on the thermal comfort of the interviewees, and draws the following conclusions:

(1) The classroom environment can meet the needs of most interviewees (college students). The reasons for dissatisfaction with the classroom environment mainly focused on the degree of air freshness, room layout and personnel density, while the number of people who were dissatisfied with the indoor temperature, relative humidity and lighting condition was small.

(2) Classroom environment can ensure the learning efficiency of the vast majority of interviewees (college students), and the influencing factors of low learning efficiency mainly focus on staying up late the night before and poor mental state.

(3) The neutral temperature of females is higher than that of males. When the relative humidity is between $50 \%$ and $60 \%$, the humidity sensation of most male and female interviewees is moderate. Women feel drier than men at the same relative humidity. At the same $\mathrm{CO}_{2}$ volume fraction in the classroom, the feeling of sufferance of female respondents is higher than that of male respondents, indicating that women are more likely to feel sufferance.

(4) The neutral temperature of obese people was lower than that of normal and lean people. Obese people are more sensitive to the perception of relative humidity, while normal and thin people are not too sensitive. When the relative humidity in the classroom is between $40 \%$ and $60 \%$, the wetness feeling of overweight people is moderate.

\section{Acknowledgements}

Foundation Project: Research achievement of "Experimental Study on Classroom Thermal Environment and Air Quality" (2020KJ22), Shandong Huayu University of Technology 2020 Annual Science and Technology Plan Project.

\section{References}

1. Liu Kuixing, Jia Yihong, Liu Gang. The influence of seasonal factors on the evaluation of human body thermal comfort in university classrooms [J]. Building Energy Conservation, 2018,46 (10) : 25-28.

2. Cao Bin. Study on the influence of climate and building environment on human thermal adaptability [D]. Beijing: Tsinghua University, 2012.

3. Cao Hongfang, Zhao Yu. Study on Human Thermal Comfort of Central Air Conditioner in Summer in Tianjin University [J]. Energy Conservation, 2019,38 (10) : 1-4.

4. Lan L, Lian Z, Liu W, et al. Investigation of gender difference in thermal comfort for Chinese people[J]. European Journal of Applied Physiology, 2008, 102(4): 471-480.

5. Dear R D, Kim J, Candido C, et al. Adaptive thermal comfort in Australian school classrooms[J]. Building Research and Information, 2015, 43(3): 383-398.

6. Rupp R F, Kim J, De Dear R, et al. Associations of occupant demographics, thermal history and obesity variables with their thermal comfort in airconditioned and mixed-mode ventilation office buildings $[\mathrm{J}]$. Building and Environment, 2018, 135(MAY): 1-9. 
7. Samar Thapa. The thermal comfort of different naturally ventilated buildings of Darjeeling, Indiaeffect of gender, age and BMI[J]. Energy and Buildings, 2019, 193: 267-288. 